Revista Verde de Agroecologia e Desenvolvimento Sustentável

http://www.gvaa.com.br/revista/index.php/RVADS

ARTIGO CIENTÍFICO

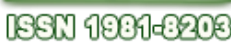

DOI: http://dx.doi.org/10.18378/rvads.v10i5.3612

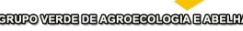

\title{
Caracterização morfobiométrica de frutos e sementes e superação da dormência em coronha (Acacia farnesiana)
}

\author{
Biometric characterization of fruits seeds and break dormancy in butt (Acacia \\ farnesiana)
}

\author{
Maria Catiana de Vasconcelos ${ }^{1}$, Francisco José Carvalho Moreira ${ }^{2}$, Maria Luciana Mesquita da Silva ${ }^{3}$, Luís Gonzaga \\ Pinheiro Neto ${ }^{4}$, Maria Cristina Martins Ribeiro de Souza ${ }^{5}$
}

\begin{abstract}
Resumo: O trabalho tem por objetivo caracterizar morfobiometricamente frutos e sementes de Acacia farnesiana além de avaliar diferentes métodos de superação da sua dormência. O trabalho foi desenvolvido no período de setembro 2014 a janeiro de 2015. As vagens foram coletadas de plantas nativas, no distrito Madeira, Sobral-CE. Para a biometria, utilizou-se 50 vagens, onde foi mensurado: comprimento, diâmetro, peso e número de sementes por vagem. Posteriormente feito o mesmo com as sementes, comprimento, largura e peso. Para a superação da dormência, utilizou-se nove tratamentos, dispostos em DIC, sendo (sementes sem escarificação, imersão em água a $80{ }^{\circ} \mathrm{C}$ por $10,20,30$ e 40 minutos, na imersão $\mathrm{em}_{2} \mathrm{SO}_{4}$ concentrado por 10 , 15,20 e 25 minutos), com quatro repetições de 16 sementes cada. A avaliação de porcentagem de germinação - (\%GER), realizou a contagem diária de plântulas emergidas, número de folhas (NF); altura da planta (AP); comprimento da raiz (CR); peso seco parte aérea (PSPA). Verificou-se que as vagens e sementes de A. farnesiana apresentam ampla variabilidade nas suas características biométricas, para as vagens com comprimento $(4,2-6,8 \mathrm{~cm})$, largura $(0,72-3,22 \mathrm{~cm})$ e peso de $(2,2-3,9$ $\mathrm{cm})$; e para as sementes com comprimento $(1,6-3,1 \mathrm{~cm})$, largura $(0,07-0,67 \mathrm{~cm})$ e peso de $(0,069-0,133 \mathrm{~cm})$. A escarificação química em $\mathrm{H}_{2} \mathrm{SO}_{4}$ nos tempos de 20 e 25 minutos e a imersão em $\mathrm{H}_{2} \mathrm{O}$ a $80{ }^{\circ} \mathrm{C}$ por 20 e 30 minutos são os métodos mais eficientes na superação da dormência de sementes de coronha.
\end{abstract}

Palavras-chave: bioma Caatinga, biometria, tratamento químico, impermeabilidade do tegumento.

\begin{abstract}
The fruits of biometrics are an important tool to detect the genetic variability of a species, defining relations between variability and environmental factors. In view of this, the work aims to characterize biometric characteristics fruits and seeds of Acacia farnesiana and to evaluate different methods of overcoming its dormancy. The study was conducted from September 2014 to January 2015. The pods were collected from native plants, district of Madeira, Sobral-CE. For biometrics, we used 50 pods, which was measured: length, diameter, weight and number of seeds per pod. Later done the same with the seeds, length, width and weight. To overcome dormancy, we used nine treatments, arranged in DIC, and (seeds without scarification, immersion in water at $80{ }^{\circ} \mathrm{C}$ for $10,20,30$ and 40 minutes of immersion in concentrated $\mathrm{H}_{2} \mathrm{SO}_{4}$ for $10,15,20$ and 25 minutes), with four replications of 16 seeds each. The germination percentage evaluation - (\%GER), held daily counts of emerged seedlings, number of leaves (NF); plant height (AP); root length (CR); dry weight shoot (PSPA). It is found that the A. farnesiana pods and seeds have wide variability of their biometric characteristics, to pods with a length $(4.2$ to $6.8 \mathrm{~cm})$, width $(0.72$ to $3.22 \mathrm{~cm})$ and weight $(2.2$ to $3.9 \mathrm{~cm})$; and seed with a length $(1.6$ to $3.1 \mathrm{~cm})$, width $(0.07$ to $0.67 \mathrm{~cm})$ and weight ( 0.069 to $0.133 \mathrm{~cm}$ ). Chemical scarification in $\mathrm{H}_{2} \mathrm{SO}_{4}$ in times of 20 and 25 minutes and immersion in $\mathrm{H}_{2} \mathrm{O}$ at $80{ }^{\circ} \mathrm{C}$ for 20 and 30 minutes are the most efficient methods to overcome dormancy of seeds of legume coronha.
\end{abstract}

Keywords: Caatinga biome, biometrics, chemical treatment, impermeability of the seed coat.

\footnotetext{
*Autor para correspondência

Recebido para publicação em 27/08/2015; aprovado em 26/12/2015

${ }^{1}$ Graduando em Irrigação e Drenagem, IFCE- Campus de Sobral, katiana.vasconcelos22@ gmail.com.: Av. Dr. Guarani, No 317 , Derby Clube, CEP: 62.042030, Sobral-CE

${ }^{2}$ Eng. Agrônomo, MSc., Professor do Eixo de Recursos Naturais, IFCE-Campus de Sobral, franzecm@gmail.com

${ }^{3}$ Eng. Agrônomo, DSc., Prof. IFCE do Eixo de Recursos Naturais - Campus Sobral, CE, luis.neto@ifce.edu.br;

${ }^{4}$ Eng. Agrônomo, DSc., Prof ${ }^{\circ}$. IFCE do Eixo de Recursos Naturais - Campus Sobral, CE, profmariacristinasouza@gmail.com
} 


\section{INTRODUÇÃO}

A coronha (Acácia farnesiana) é uma planta pertencente à Família Fabaceae, sendo espinhenta, de 4-7 metros de altura, dotada de copa larga e baixa e tronco curto e tortuoso, com casca quase lisa e lenticelada, de 15-35 centímetros de diâmetro. Esta espécie ocorre na mata atlântica e no pantanal matogrossense, nas formações semidecíduas de terrenos calcários e pedregosos, e ocorre também no Paraguai e na Bolívia. (LORENZI, 2002)

A madeira desta espécie é indicada para dormentes, moirões, esteios, eixos e rodas, rolos para moendas, construção civil, peças de resistência, cabos de instrumentos, lenha e carvão. As raízes, de cheiro aliáceo, a casca e as folhas são reputadas como medicinais e parasiticidas. As flores perfumadas indicam uso no paisagismo em geral (LORENZI, 2002).

No entanto, a biometria dos frutos constituem como um instrumento importante para detectar a variabilidade genética dentro de populações de uma mesma espécie, e na definição de relações entre esta variabilidade e os fatores ambientais, fornecendo importantes informações para a caracterização dos aspectos ecológicos como o tipo de dispersão, agentes dispersores e estabelecimento das mudas (CARVALHO et al., 2003; MATHEUS; LOPES, 2007; ABREU et al,. 2015).

Já a classificação das sementes por tamanho ou por peso é uma estratégia importante que pode ser adotada para uniformizar a emergência das plântulas e para a obtenção de mudas de tamanho semelhante ou de maior vigor (CARVALHO; NAKAGAWA, 2000).

A importância dos estudos biométricos de frutos e de sementes já foi estudadas por vários pesquisadores, como ferramenta fundamental para a compreensão e descrição do processo germinativo (ABREU et al., 2005), para o armazenamento e realização de testes de qualidade e conhecimentos das características físicas e anatômicas do tecido de cobertura nesse caso para a aplicação de tratamentos para promover a germinação das sementes (PEREZ, 2004).

$\mathrm{O}$ estudo da biometria de frutos e sementes contribui para identificação botânica das espécies (Araújo Neto et al. 2002; Amaro et al., 2006), proporcionando a diferenciação de espécies do mesmo gênero.

Todavia, é corriqueira a manifestação da dormência em sementes de espécies florestais. Segundo Silva et al. (2012) a dormência é caracterizada pelo atraso na germinação, quando as sementes, mesmo em condições favoráveis não germinam. Essa característica pode ser fundamental para a permanência da espécie em campo, quando as condições climáticas não são favoráveis para o estabelecimento das mesmas. (ALVES et al. 2014). Porém, essa é uma característica indesejável para os viveiristas, cuja dormência acaba por gerar problemas como desuniformidade entre as mudas.

Alguns métodos são recomendados para a superação da dormência das sementes, como tratamentos químicos, escarificação mecânica e tratamento térmico com o uso de temperaturas elevadas. A eficiência do tratamento é variável segundo a espécie.

Um artifício bastante utilizado para a quebra da dormência tegumentar é o ácido sulfúrico, no entanto a sua eficiência está relacionada com o tempo de exposição ao ácido e à da espécie. De acordo com Costa et al. (2010), para sementes de
Adenanthera pavonina L. o uso desse ácido concentrado (98\%), durante 5 ou 10 minutos, foi o melhor método para quebra de dormência promovendo resultados satisfatórios na percentagem de germinação $(85 \%)$.

Em função do exposto, o trabalho tem por objetivo caracterizar morfobiometricamente frutos e sementes de Acacia farnesiana e avaliar diferentes métodos de superação da dormência.

\section{MATERIAL E MÉTODOS}

O trabalho foi desenvolvido no período de setembro 2014 a janeiro de 2015. Os experimentos foram conduzidos no Laboratório de Fitossanidade e Sementes e no Telado Agrícola, ambos no IFCE - Campus Sobral, locado nas coordenadas geográficas $\left(03^{\circ} 40^{\prime} \mathrm{S}\right.$ e $\left.40^{\circ} 14^{\prime} \mathrm{W}\right)$. O clima é classificado de acordo Koppen como Aw', tropical quente chuvoso semiárido com pluviometria média anual de 854 $\mathrm{mm}$, temperatura média de $28^{\circ} \mathrm{C}$ e a altitude de 70 metros.

Os frutos foram coletados de plantas nativas, no distrito Madeira, município de Sobral, CE. Em seguida, foram levadas ao Laboratório de Fitossanidade e Sementes, processadas, limpas e armazenadas em refrigerador até o início das análises.

Foram desenvolvidos dois ensaios, senso o primeiro para caracterizar biometricamente os frutos e as sementes de coronha, e o segundo para avaliar o desempenho germinativo das sementes em função dos tratamentos para a quebra da dormência.

Foram selecionadas e avaliadas 50 vagens, para serem mensurados os seguintes caracteres: comprimento, diâmetro, peso e número de sementes por vagem. Posteriormente feito o mesmo com as sementes, comprimento, largura e peso. $\mathrm{O}$ comprimento foi realizado com régua graduada em centímetros, para o diâmetro utilizou-se paquímetro digital DIGIMESS $^{\circledR}$, graduado em milímetro e para os pesos usou-se balança analítica de marca Kern ${ }^{\circledR} 770$, obtendo-se assim valores em gramas. Realizou-se ainda o peso de 1.000 sementes, conforme (BRASIL, 2009).

Distribuição de frequência dos dados foram divididos em cinco classes, seguindo a regra de Sturges $(K=1+3,33 \log$ (N); conforme amplitude dos dados ( $\mathrm{L}=$ Xmáx - Xmin); e com amplitude de classes $(h=L / k)$, sendo, em seguida, calculado os limites das Classes, sendo:

$$
\begin{aligned}
& \text { 1 a Classe: Xmín até Xmín }+\mathrm{h} \\
& 2^{\text {a }} \text { Classe: Xmín até Xmín }+2 . h \\
& \text { K } \text { Classe: Xmín }+(\mathrm{k}-1) \text {. h até Xmín }+\mathrm{k} \text {. h }
\end{aligned}
$$

Para o segundo ensaio, utilizou-se cinco bandejas de isopor com 128 células cada, efetuando-se a semeadura no dia 04 de dezembro de 2014, colocando-se uma semente por célula. O ensaio foi disposto em Delineamento Inteiramente Casualizado - DIC, com nove tratamentos (testemunha - sem escarificação, imersão em água a $80^{\circ} \mathrm{C}$ por $10,20,30$ e 40 minutos, imersão das sementes em $\mathrm{H}_{2} \mathrm{SO}_{4}$ concentrado por $10,15,20$ e 25 minutos. Utilizaram-se quatro repetições de 16 sementes cada, caracterizando assim a unidade experimental. Para a manutenção do substrato com a umidade propicia à germinação, as irrigações eram feitas duas vezes ao dia, com $\mathrm{o}$ intuito de manter o substrato propício à germinação.

Aos 20 dais após a semeadura procedeu-se da avaliação final deste ensaio, mensurando-se as seguintes variáveis: 
porcentagem de germinação - (\%GER), de acordo com a RAS (BRASIL, 2009), a qual foi realizada com a contagem diária de plântulas normais, sendo resultado expresso em porcentagem; tempo média de germinação (TMG); número de folhas (NF); altura da planta (AP); comprimento da raiz (CR); peso seco parte aérea (PSPA).

Os dados submetidos à análise de variância pelo teste $\mathrm{F}$, utilizando o programa Assistat ${ }^{\circledR} 7.7$ Beta. Quando houve significância, as médias foram comparadas pelo teste de Tukey. Os resultados foram apresentados em Tabelas e Gráficos.

Os dados foram analisados e agrupados em distribuição de frequência, em cinco classes, além disso, efetuaram-se as médias, limite inferior, limite superior, desvio padrão e coeficiente de variação de cada amostra. Os resultados foram apresentados em Tabelas e Gráficos.

\section{RESULTADOS E DISCUSSÃO}

De acordo com a análise da Tabela 1, observa-se que todos os parâmetros biométricos das vagens obtiveram um melhor rendimento para Classe $\mathrm{V}$, nas variâncias de comprimento $(5,76-6,28 \mathrm{~cm})$, largura $(2,72-3,22 \mathrm{~cm})$, peso $(3,621$ - 3,951 g) e número de sementes por vagens $(19,8-$ 22) e em quanto que a Classe I apresentou os menores valores já mencionados, tendo os seus desvios padrão de $(0,4861$ 2,7004).

Tabela 1. Dados biométricos de distribuição de classes, limite inferior, limite superior, média, desvio padrão e coeficiente de variação das vagens de coronha, das variáveis comprimento (comp.), largura (larg.), peso e número de sementes por vagem s.vg ${ }^{-1}$. IFCE - campus sobral. Sobral-CE, 2016.

\begin{tabular}{lcccc}
\hline & \multicolumn{4}{c}{ Dados Biométricos das Vagens } \\
\cline { 2 - 5 } & Comp. (mm) & Larg. (mm) & Peso (g) & $\mathrm{N}^{0} \mathrm{SVg}^{-1}$ \\
\hline Classe I & $4,2-4,72$ & $0,72-1,222$ & $2,2-2,5516$ & $11-13,2$ \\
Classe II & $4,72-5,24$ & $1,22-1,722$ & $2,55-2,9016$ & $13,2-15,4$ \\
Classe III & $5,24-5,76$ & $1,72-2,222$ & $2,9-3,2516$ & $15,4-17,6$ \\
Classe IV & $5,76-6,28$ & $2,22-2,722$ & $3,25-3,6016$ & $17,6-19,8$ \\
Classe V & $6,28-6,8$ & $2,72-3,222$ & $3,6-3,9516$ & $19,8-22$ \\
\hline Lim. Inf & 4,2 & 0,72 & 2,2 & 11 \\
Lim. Sup & 6,8 & 3,22 & 3,95 & 22 \\
Média & 5,34 & 2,14 & 3,13 & 15,28 \\
Des. Padrão & 0,4861 & 0,6994 & 0,4470 & 2,7004 \\
CV(\%) & 9,09 & 32,75 & 14,27 & 17,68 \\
\hline
\end{tabular}

Com base nos dados analisados na Tabela 1, a melhor classe de sementes estudadas nas variâncias apresentou-se na Classe V. Assim mostrados nos parâmetros acima, no qual apresenta a classe que obteve um melhor incide em seus aspectos físicos e morfológicos. Já para os menores valores obtidos em todas as variâncias encontra-se na Classe I.
Figura 1. Parâmetros analisados da vagem: comprimento da vagem, que obteve o melhor resultado Classe III (A), o diâmetro Classes IV e V (B), já para o peso encontrado Classes II e III (C) e por último e de grande importância o número de sementes por vagem que teve uma maior relevância foi a da Classe II (D).
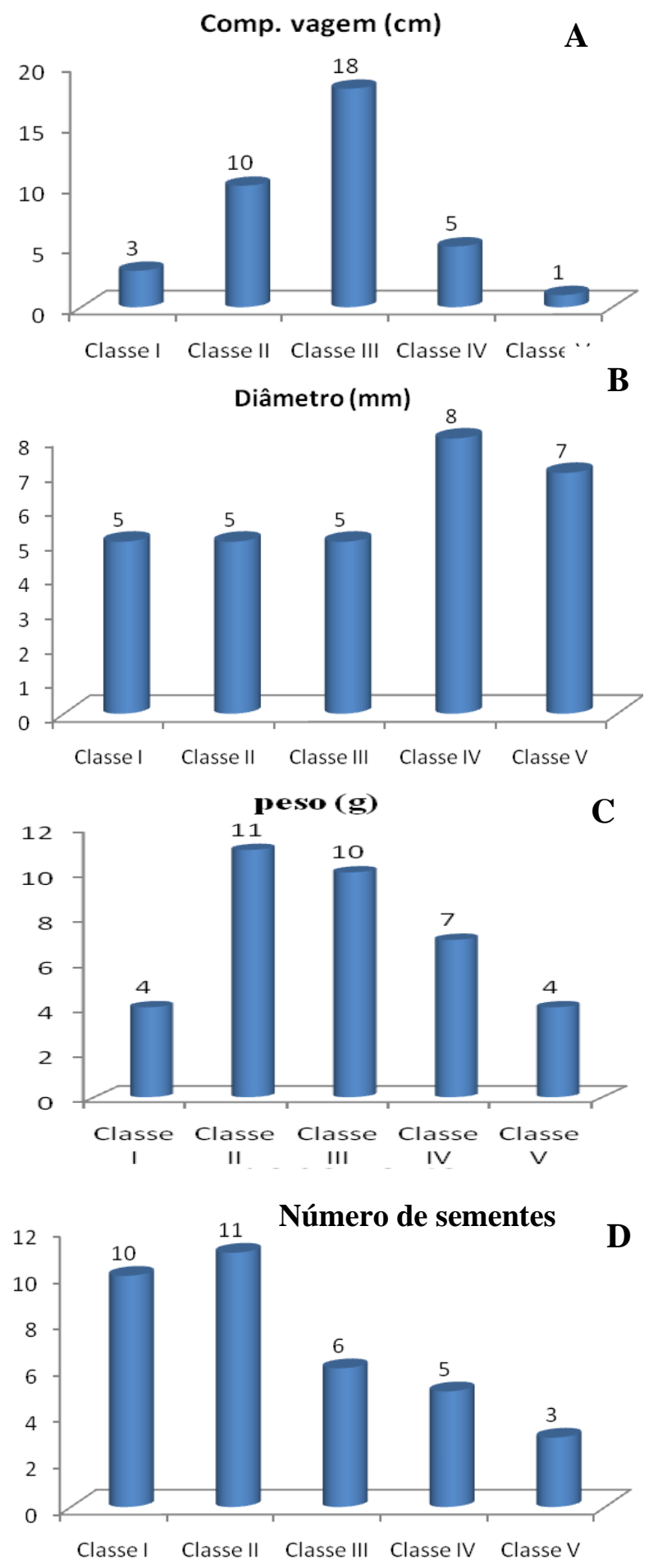

Na Figura (1A) comprimento da vagem a classe III foi a que obteve maiores comprimento de Acácia farnesiana diferente da classe I com menor valor. Na figura (1B) para o diâmetro a classe IV e V tiveram valores superiores as I, II e III com diâmetros iguais. Figura (1C) peso da à classe II e III tiveram maiores peso, e a figura (1D) números de sementes, II obteve maior número de sementes por vagem. 
Tabela 2. Dados biométricos de distribuição de Classes, limite inferior, limite superior, média, desvio padrão e coeficiente de variação (CV) das sementes de coronha dos variáveis comprimentos (Comp.), largura (Larg.) e o peso. IFCE - Campus Sobral, Sobral-CE, 2015.

\begin{tabular}{lccc}
\hline & \multicolumn{3}{c}{ Dados Biométricos das Sementes } \\
\cline { 2 - 4 } & Comp. $(\mathrm{mm})$ & Larg.(mm) & Peso (g) \\
\hline Classe I & $1,6-1,984$ & $0,07-0,192$ & $0,0698-0,0826$ \\
Classe II & $1,984-2,368$ & $0,19-0,312$ & $0,0826-0,0954$ \\
Classe III & $2,368-2,752$ & $0,31-0,432$ & $0,0954-0,1082$ \\
Classe IV & $2,752-3,136$ & $0,43-0,552$ & $0,1082-0,1210$ \\
Classe V & $3,136-3,52$ & $0,55-0,672$ & $0,121-0,1338$ \\
\hline Lim. Inf & 3,52 & 0,68 & 0,134 \\
Lim. Sup. & 1,60 & 0,07 & 0,068 \\
Média & 2,76 & 0,20 & 0,12 \\
Des. Padrão & 0,5019 & 0,1057 & 0,1340 \\
CV(\%) & 18,17 & 52,04 & 109,12 \\
\hline
\end{tabular}

Normalmente, frutos e sementes de espécies nativas apresentam maior variabilidade de suas características em relação às espécies cultivadas. Isso pode ocorrer em razão da grande diversidade genética existente entre as plantas dessas espécies, sobre as quais diferentemente das cultivadas/domesticadas, não foram realizados estudos de melhoramento genético nem das características físicas e morfológicas (MOREIRA et al. 2011; ARAÚJO et al. 2015).

Portanto, o estudo das características biométricas de frutos e sementes, assim como a variabilidade das mesmas são muito importantes para o melhoramento dessas características, seja no sentido de potencializar ou uniformizálas. Assim, a estratificação das sementes por tamanho, peso e quantidade por planta/vagem pode ser uma maneira de aprimorar os lotes em relação à uniformidade de emergência e vigor das plântulas.

Corroborando estas informações, para Vieira e Gusmão (2008), essas variações podem ser decorrentes de variabilidade genética ou de plasticidade fenotípica determinadas pelas variações ambientais em função das diferentes localidades geográficas.

A caracterização biométrica de frutos e de sementes tem importância para a taxonomia, na identificação de variedades e para verificar a ocorrência de variações fenotípicas.

O resumo da análise de variância da percentagem de germinação (\%), tempo médio de germinação (TMG), altura da planta (AP), número de folhas (NF), comprimento da raiz (RZ), peso seco da planta (PSP) de semente de coronha em função da imersão em água a $80^{\circ} \mathrm{C}$ por $(10,20,30$ e $40 \mathrm{~min})$ minutos, na imersão em $\mathrm{H}_{2} \mathrm{SO}_{4}$ concentrado por $(10,15,20 \mathrm{e}$ 25 min) encontram-se na Tabela 3.

Observa-se que para a variável percentagem de germinação (\%), tempo médio de germinação (TMG), altura da planta (AP), número de folhas (NF), comprimento da raiz (CR) e peso seco da planta (PSP) analisado houve diferença significativa pelo teste de "F" a $1,0 \%$ e $5,0 \%$ de probabilidade.
Figura 2. Representação dos resultados das variâncias da semente: como obsevado na Figura (A), a semente selecionada teve o seu comprimento de (3 -12 mm), sendo com maior relevancia a Classe $\mathrm{V}$; para largura a melhor foi a da Classe I sendo (22 mm) (B); e peso variou entre (6-10 g) (C).

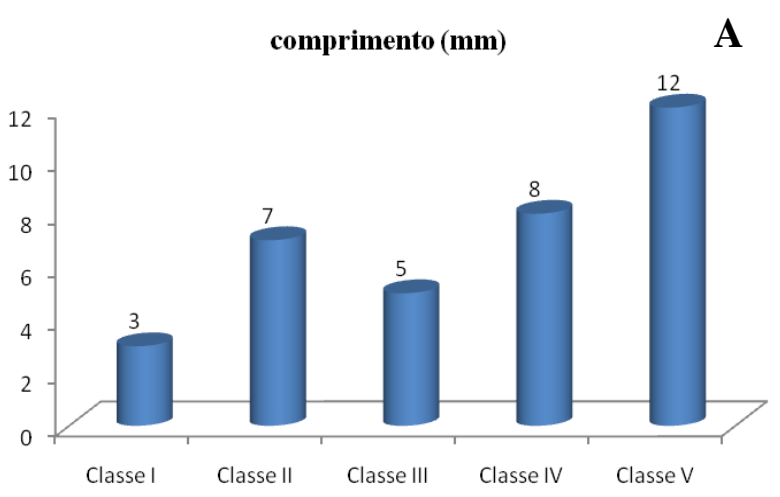

Largura (mm)

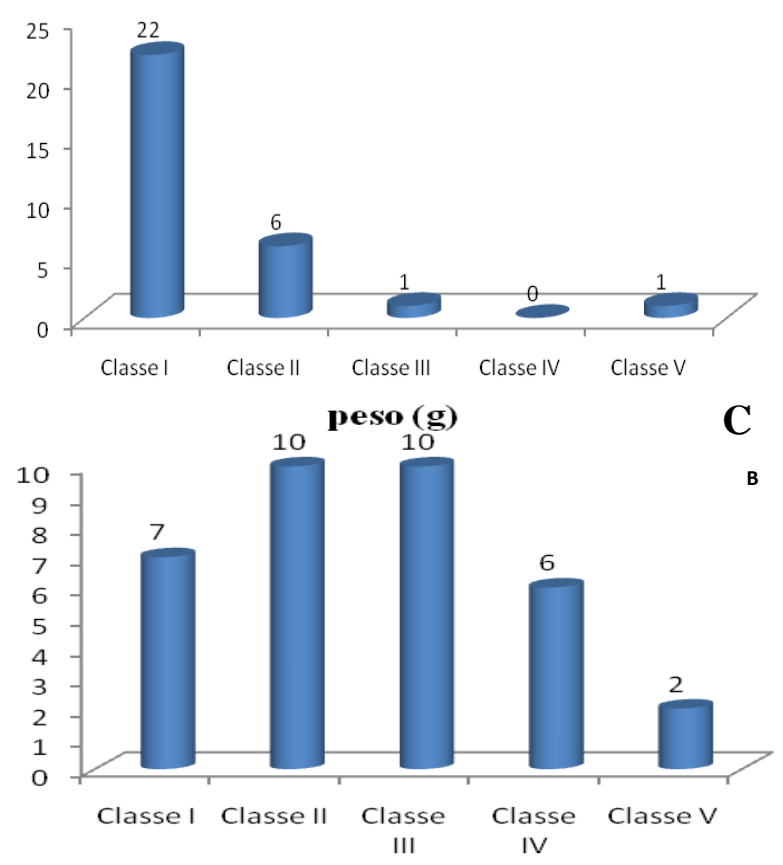

Tabela 3. Valores médios percentagem de germinação (\%), tempo médio de germinação (TMG), número de Folhas (NF), Altura da Planta (AP), Cumprimento da Raiz (CR), Peso seco da planta (PSP). Em função da imersão em água a $80^{\circ} \mathrm{C}$ por $(10,20,30$ e 40$)$ minutos, na imersão em $\mathrm{H}_{2} \mathrm{SO}_{4}$ concentrado por (10, 15, 20 e 25 minutos). IFCE - Campus Sobral, SobralCE. 2015.

\begin{tabular}{lccccccc}
\hline Fontes de & \multirow{2}{*}{\begin{tabular}{c}
\multicolumn{7}{c}{ Quadrados Médios } \\
variação
\end{tabular}} & G.L. & \multicolumn{7}{c}{ Ger $(\%)$} & TMG & AP & NF & CR & PSP \\
\hline Tratamentos & 8 & $491,878^{*}$ & $31,686^{* *}$ & $0,3946^{*}$ & $3945,48^{* *}$ & $3,9917^{* *}$ & $0,06434^{* *}$ \\
Resíduo & 27 & 168,2045 & 3,21179 & 0,15577 & 1113,145 & 1,22534 & 0,01469 \\
\hline DMS & - & 30,867 & 4,2653 & 0,93933 & 79,40594 & 2,63455 & 0,28850 \\
CV $(\%)$ & - & 89,18 & 48,63 & 91,45 & 92,14 & 102,22 & 81,57 \\
\hline
\end{tabular}

* valor significativo a 5,0\% pelo teste $\mathrm{F}$., ** valor significativo a $1,0 \%$ pelo teste $\mathrm{F}$, ns valor não significativo. 
Figura $3 \mathrm{~A}$ valores médios de percentagem de germinação (\%GER), 3B valores médios tempo médio de germinação (TMG), 3C altura da planta (AP) e em 3D número de folha de plantas de coronha em função da imersão em água a $80{ }^{\circ} \mathrm{C}$ por $(10,20,30$ e $40 \mathrm{~min})$ e imersão em $\mathrm{H}_{2} \mathrm{SO}_{4}$ concentrado por $(10,15,20$ e 25 min.).

$\mathrm{Na}$ Figura 3A, As sementes de coronha (Acacia farnesiana.) não emitida em água e ácido sulfúrico não houve germinação. Quando submetida em $\mathrm{H}_{2} \mathrm{O}$ nos tempos de 10, 20 e 30 minutos não apresentam diferença significativa. As sementes escarificadas com ácido sulfúrico nos tempos de 20 e 25 minutos apresentaram melhor desempenho germinativo. $\mathrm{Na}$ Figura 3B, na imersão em ácido sulfúrico $\left(\mathrm{H}_{2} \mathrm{SO}_{4}\right)$ nos tempos 20 e 25 minutos houve um melhor tempo médio de germinação.

Figura 3. Em A - comprimento da raiz; em B - peso seco da planta de sementes de coronha submetidas a sete tratamentos para a superação da dormência. IFCE - Campus Sobral. Sobral, CE, 2015.

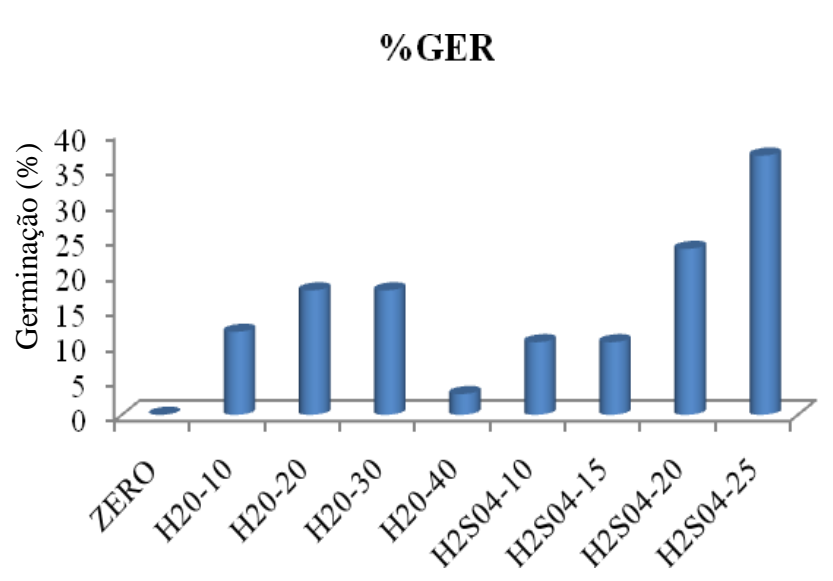

Tratamentos

\section{TMG}

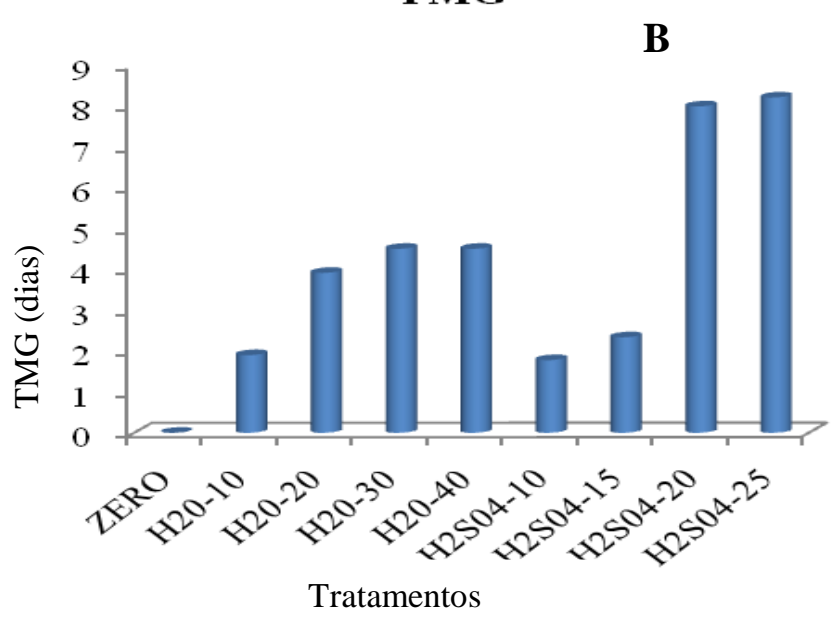

No entanto, algumas espécies, pela espessura do tegumento, suportam longos períodos de exposição a esta substância. Em estudo realizado por Cruz et al., (2007), foram obtidas, com sementes de Schizolobium amazonicum Huber ex Ducke, as maiores porcentagens de germinação (92\%), quando submetidas à escarificação química, com imersão em ácido sulfúrico por 60 minutos.
$\mathrm{Na}$ Figura 4A, as sementes escarificadas com ácido sulfúrico $\left(\mathrm{H}_{2} \mathrm{SO}_{4}\right)$ concentrado por 25 minutos apresentaram uma altura de $1,05 \mathrm{~cm}$ para as plântulas mostrando superior aos outros tratamentos, já os tratamentos $\mathrm{H}_{2} \mathrm{O}-20{ }^{\circ} \mathrm{C}$ e $\mathrm{H}_{2} \mathrm{O}-$ $30{ }^{\circ} \mathrm{C}$ não apresentaram diferenças estatísticas entre si. $\mathrm{Na}$ Figura 4B, mostra que o número de folhas proporcionou- se melhor resultado quando submetido escarificadas com $\mathrm{H}_{2} \mathrm{SO}_{4}$ por 25 minutos obtendo um melhor rendimento.

Figura 4. A. Altura da planta; em B - número de folhas de sementes de coronha submetidas a sete tratamentos para a superação da dormência. IFCE - Campus Sobral. Sobral, CE, 2016.
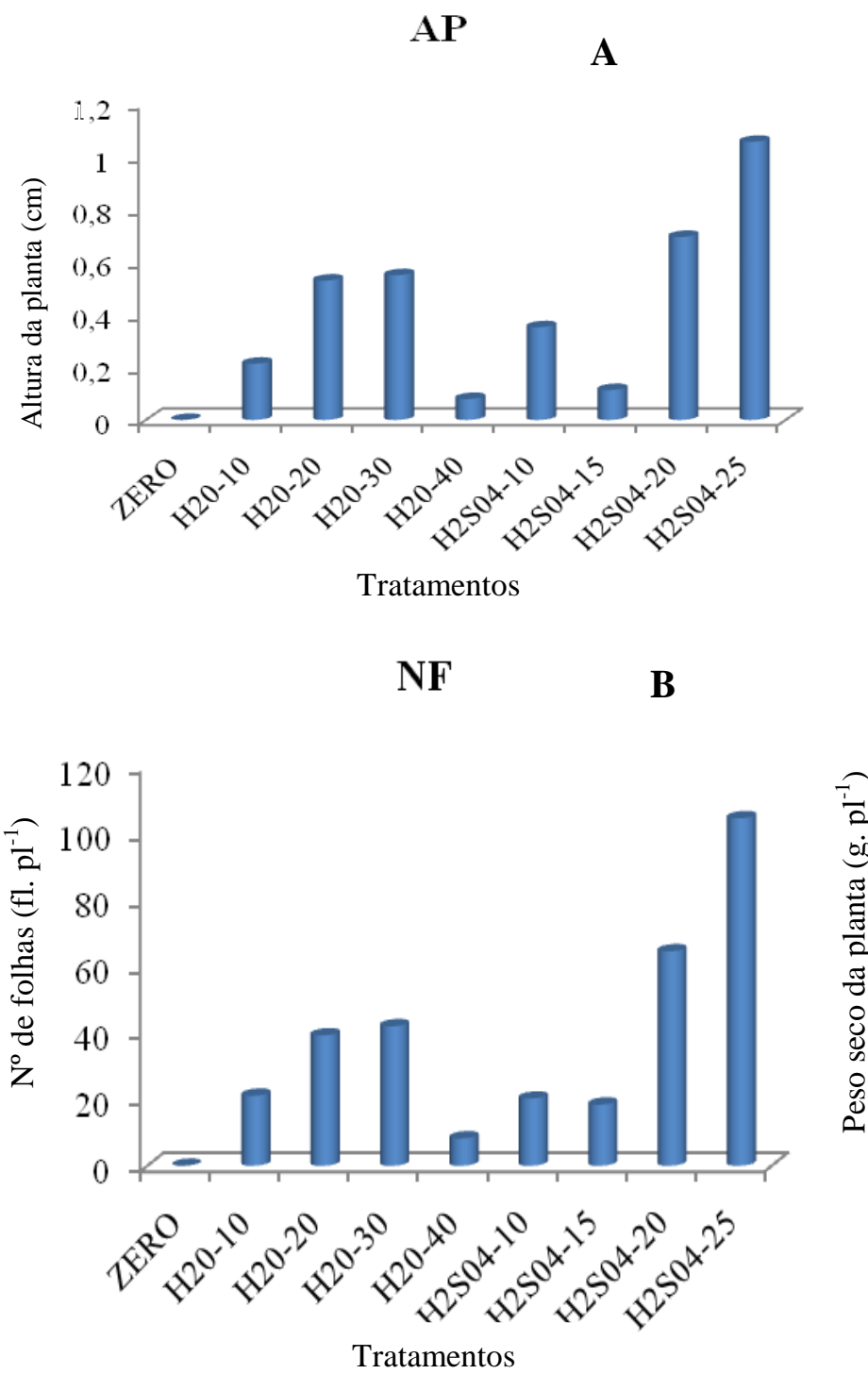

Observa-se na Figura 5A, valores médios de comprimento da raiz (CR) e em (5B) valores médios peso seco das plantas (PSP) de plantas de coronha em função da imersão em água a $80^{\circ} \mathrm{C}$ por $(10,20,30$ e $40 \mathrm{~min})$ e imersão em $\mathrm{H}_{2} \mathrm{SO}_{4}$ concentrado por (10,15 e $20 \mathrm{~min}$.). 
Figura 5. Em A - comprimento da raiz; em B - peso seco da planta de sementes de coronha submetidas a sete tratamentos para a superação da dormência. IFCE - Campus Sobral. Sobral, CE, 2016.

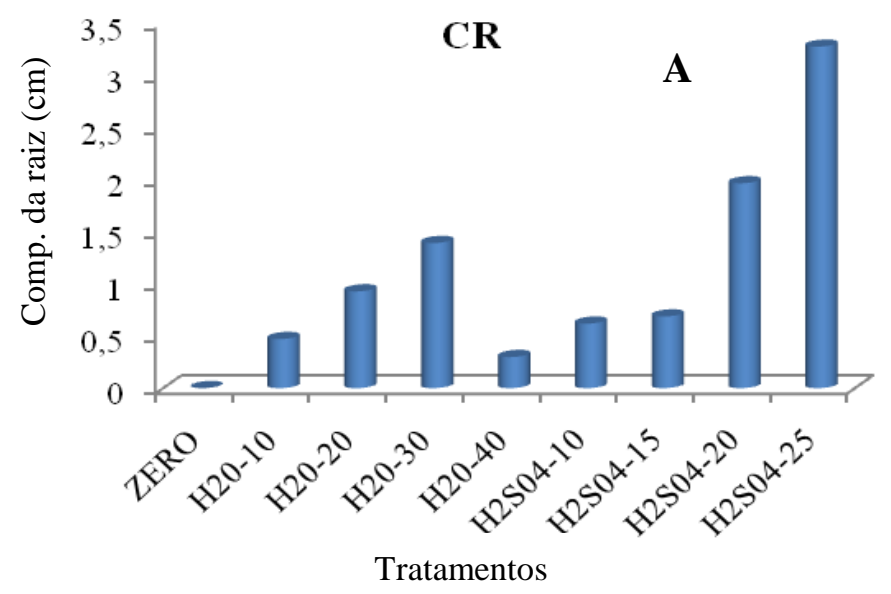

PSP

B

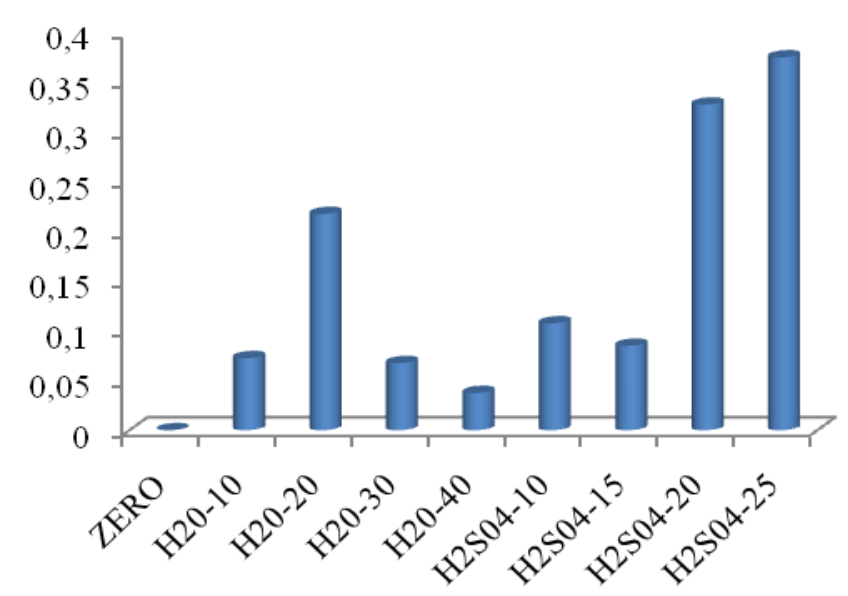

Tratamentos

Os resultados deste ensaio mostram-se auspiciosos, visto que a dormência acaba dificultando o planejamento dos viveiristas para a obtenção de mudas, pois tem-se observado que a cada dia o uso de espécies nativas arbóreas para programas de reflorestamento em manejo sustentável ou, ainda, para a arborização urbana, como medicinais vem se intensificando nos últimos anos e, muitas dessas espécies, apresentam mecanismos de dormência (ZAIDAN \& BARBEDO, 2004).

Portanto, a escarificação química $\left(\mathrm{H}_{2} \mathrm{SO}_{4}\right)$ e térmica (água quente) das sementes proporcionou um método fácil e rápido da superação da dormência das sementes de coronha, confirmando a necessidade da sua utilização para uma germinação rápida e uniforme.

Dessa forma, comprova-se que o conhecimento de métodos mais eficazes e menos dispendiosos para superação da dormência nas espécies de A. farnesiana podem levar a obtenção de grande quantidade de sementes germinadas para o estabelecimento rápido dessas espécies a campo. Contudo, deve ser levado em conta que o ácido sulfúrico concentrado apresenta desvantagens como perigo no seu manuseio, pelo alto poder corrosivo e pela violenta reação com a água, elevando a temperatura e causando respingos que podem provocar queimaduras.

\section{CONCLUSÕES}

A escarificação química em ácido sulfúrico nos tempos de 20 e 25 minutos e a imersão em água a $80^{\circ} \mathrm{C}$ por 20 e 30 minutos são os métodos mais eficientes na superação da dormência de sementes de coronha.

As vagens de $A$. farnesiana apresentaram variação em suas características comprimento $(4,2-6,8 \mathrm{~cm})$, largura $(0,72-3,22 \mathrm{~cm})$ e peso de $(2,2-3,9 \mathrm{~cm})$;

As sementes de A. farnesiana apresentaram variação em suas características comprimento $(1,6-3,1 \mathrm{~cm})$, largura $(0,07-0,67 \mathrm{~cm})$ e peso de $(0,069-0,133 \mathrm{~cm})$;

Frutos e sementes de A. farnesiana apresentam ampla variabilidade nas suas características biométricas.

\section{AGRADECIMENTOS}

A primeira autora agradece a FUNCAP pela concessão de bolsa de Iniciação Científica. Ao IFCE - Campus Sobral pela oportunidade de desenvolver a pesquisa. E em especial aos professores Luis Gonzaga Pinheiro Neto e Francisco José Carvalho Moreira por mim ajudarem na pesquisa realizada.

\section{REFERÊNCIAS BIBLIOGRÁFICAS}

ALVES, A. U. et al. Superação da dormência de sementes de Bauhinia divaricata L. Acta Botânica Brasílica, Porto Alegre, RS, v. 18, n.4, p.871-879, 2014.

ARAÚJO, B. de A.; SILVA, M. C. B. da; MOREIRA, F. J. C.; SILVA, K. da F.; TAVARES, M. K. das N. Caracterização biométrica de frutos e sementes, química e rendimento de polpa de juazeiro (Ziziphus joaseiro Mart.). Agropecuária Científica no Semiárido - ACSA. v. 11, n. 2, p. 15-21, Abr - Jun, 2015. Disponível em: http://150.165.111.246/ojspatos/index.php/ACSA/article/view/605. Acesso: 22 ago. 2015.

BRASIL. Ministério da Agricultura, e Reforma Agrária. Regras para análise de sementes. Brasileira sobre Sementes e Mudas. Brasília: MAPA /ACS, 399p. 2009.

CARVALHO, J. E. U.; NAZARÉ, R.F.R.; OLIVEIRA, W. M. Características físicas e físico-químicas de um tipo de bacuri (Platonia insignis Mart.) com rendimento industrial superior. Revista Brasileira de Fruticultura. Cruz das Almas, v. 25, p. 326-328, 2003.

BARBOSA, A. P.; SAMPAIO, P. de T. B.; CAMPOS, M. A. A.; VARELA, V. P.; GONÇALVES, C. de Q. B.; IIDA, S. Tecnologia alternativa para a quebra de dormência das sementes de pau-de-balsa (Ochroma lagopus Sw., Bombacaceae). Acta Amazônica, Manaus, v. 34, n. 1, p. 107-110, 2004.

CORREIA JUNIOR, C.; CASTELLANE, P.D.; JORGE NETO, J. Influência adubação orgânica e química na produção de capítulos florais, conteúdo e composição do óleo essencial da camomila (Chamomilla recutita [L.] Rauschert). em: congresso mundial de plantas aromáticas e medicinais de uso humano BEM-ESTAR, 
2. Mendonza, 10-15 novembro de 1997. Mendonza, ICMAP, ISHS e SAIPA de 1997. O-010. Abstratos. 2004

CRUZ, D. E.; CARVALHO, J. E. L.; QUEIROZ，RJB escarificação com ácido sulfúrico de Huber ex Ducke Schizolobium amazonicum sementes - Leguminosae. Scientia Agricola, Piracicaba, v. 64, n. 03, p. 308-313, maio / junho De 2007.

FOURNIER, L. A. Un método cuantitativo para La medición de características fenológicas en árbores. Turrialba, v. 24, n. 4, p. 422-423, 1974.

FUNCEME. Disponível em: http://www.funceme.br/index.php/areas. Acesso: $14 \mathrm{dez}$. 2014.

GHEYI, H. R.; FAGERIA, N. K. Efeito dos sais sobre as plantas. In: Manejo e controle da salinidade na agricultura irrigada. Campina Grande, PB: UFPB p.125$131,1997$.

MOREIRA, F. J. C.; FERNANDES, G. M. A. MELO, F. R. P.; ARAÚJO, P. G. L. Morfobiometria de frutos e rendimento de polpa de juá (Ziziphus joaseiro Mart.). VI Congresso de Pesquisa e Inovação da Rede Norte Nordeste de Educação Tecnológica - VI CONNEPI. Anais..., Natal-RN. 10p. 2011.
HERMANSEN, L. A.; DUYEA, M. L.; WHITE, TL Variabilidade na semente casaco dormência em Dimorphandra mollis. Semente de Ciência e Tecnologia, Zurique, v. 28, n. 3, p. 567- 580, 2000.

ROCHA FILHO, L.C. da.; LOMONACO, C. Variações fenotípicas em subpopulações de Davilla elliptica A. St.-Hil. (Dilleniaceae) e Byrsonima intermedia A. Juss. (Malpighiaceae) em uma área de transição cerradovereda. Acta Botânica Brasílica. v. 20, n. 3, p.719-725, 2006.

Projeto Plantas do Futuro, Projeto Plantas do Futuro Listas 1, 2 e 3 de Medicinal CNIP-APNE. 2005.

VIEIRA, F. A.; GUSMÃO, E. Biometria, armazenamento de sementes e emergência de plântulas de Talisia esculenta Radlk. (Sapindaceae). Ciência Agrotécnica. Lavras, v.32, n.4, p.1073 - 1079, 2008.

SMIDERLE, O. J.; SOUSA, R. C. P. Dormência em sementes de paricarana (Bowdichia virgilioides Kunth FABACEAE - PAPILIONIDAE). Revista Brasileira de Sementes, vol. 25, $\mathrm{n}^{\mathrm{o}}$ 1, p.72-75, 2003

ZAIDAN, L.B.P.; BARBEDO, C.J. Quebra de dormência em sementes. In: FERREIRA, A. G.; BORGHETTI, F. (Org.). Germinação: do básico ao aplicado. Porto Alegre: Artmed, p.135-146. 2004. 